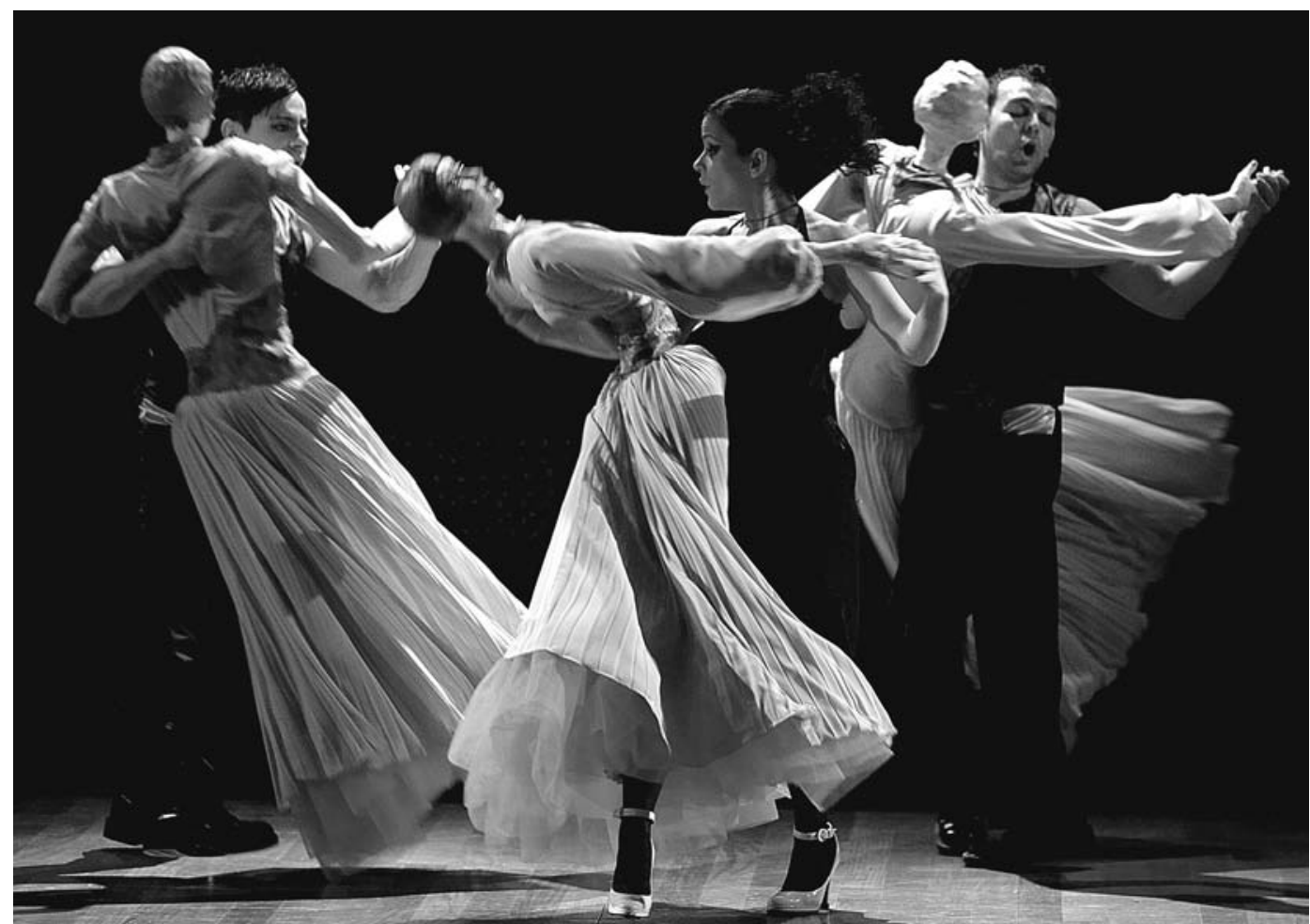

\title{
Um teatro poético e popular
}

\section{Paulo Eduardo Carvalho}

Titulo: Cabaret Molotov. Encenação e cenografia: João Paulo Seara Cardoso. Marionetas: Erika Takeda. Figurinos: Pedro Ribeiro. Coordenação coreográfica: Isabel Barros. Música: Gotan Project, Eric Satie, Kurt Weil, Robert Miny, Yann Tirsen. Desenho de luz: António Real e Rui Pedro Rodrigues. Interpretação: Edgard Fernandes, Sara Henriques, Sérgio Rolo e Shirley Resende (instrumentista). Produção: Teatro de Marionetas do Porto. Produção executiva:Sofia Carvalho. Local e data de estreia: Convento de S. Bento da Vitória, Porto, 7 de Dezembro de 2006.

Numa entrevista publicada no $4 .{ }^{\circ}$ número da Sinais de cena, João Paulo Seara Cardoso partilhava uma das mais centrais premissas de muitos dos espectáculos do Teatro de Marionetas do Porto, a companhia que há largos anos dirige e que é um dos casos de maior felicidade criativa da nossa paisagem teatral contemporânea:

\footnotetext{
A nossa forma de fazer teatro assenta fundamentalmente na ideia de expor aos olhos do público a marioneta e o actor em relação intima com os outros elementos cénicos, e explorar a dialéctica que dai advém. Neste contexto seria altamente restritivo usar só as marionetas, porque a marioneta não pode existir teatralmente sem o actor, elemento essencial da teatralidade. E o que é belo e ao mesmo tempo brutal nisto tudo é o confronto entre os actores e as marionetas: tanto um actor que manipula uma marioneta, como um actor que contracena com uma marioneta ou como os actores que vivem no mesmo universo, quase onirico, das marionetas. É todo este jogo, muito sedutor, toda esta dialéctica, de vida e de morte, de existência efémera, que pode provocar um estado especial em quem assiste a um espectáculo. (Cardoso 2005: 61-62).
}

Esta sintese exacta, então esboçada para recuperar o conjunto de processos cénicos que vinham orientando o percurso daquela companhia, serve ainda para caracterizar um dos mais recentes e mais conseguidos espectáculos de João Paulo Seara Cardoso. Apresentado como o resultado de um contínuo "trabalho de experimentação", Cabaret Molotov leva um pouco mais longe o assumido investimento na manipulação à vista, isto é, na exploração performativa da indissociável articulação entre o intérprete e a marioneta ou, como o criador prefere, o "objecto cinético" - expressão mais justa, na realidade, para designar a multiplicidade de objectos animados pelos manipuladores, desde o boneco mais antropomórfico até à simples bola vermelha ou ao mais elementar bocado de madeira, sem qualquer expressão antes daquela que lhe emprestarão o corpo e a voz dos actores.

0 criador cruza neste seu espectáculo a linguagem das marionetas com o imaginário e alguns dos recursos do circo, do cabaré e do music-hall, tirando o máximo partido da maleabilidade dessas formas populares de teatro. Historicamente anteriores à sistematização teórica e às experiências concretas de um "teatro popular" de ambições democráticas, proletárias e politicamente progressistas, estas tradições performativas tinham tradicionalmente 0 entretenimento como ambição dominante e caracterizavamse por uma ostensiva despretensão artística e intelectual. Tal facto não impediu que tivessem servido, e continuem a servir, de estímulo para as pesquisas artísticas de alguns dos mais ousados criadores teatrais contemporâneos, que nelas vislumbraram um enorme potencial transgressivo e uma peculiar permeabilidade às mais variadas operações 


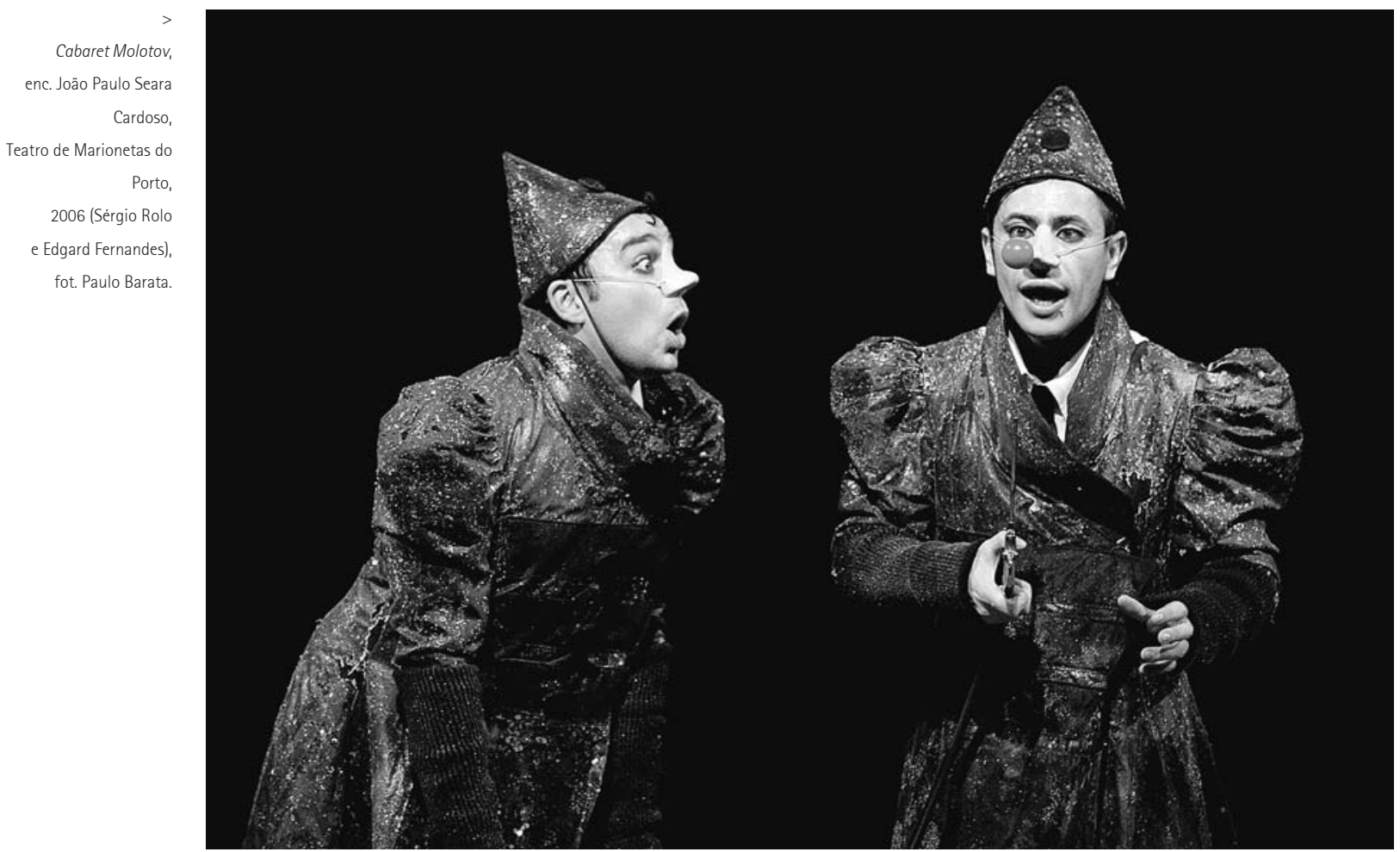

de adaptação, reinterpretação e reconfiguração cénica (cf. Schechter 2003).

Dado o manifesto interesse de João Paulo Seara Cardoso pelo cruzamento de disciplinas ou universos artísticos e pela exploração das suas mais imprevistas fertilizações, não deverá surpreender esta convocação do circo e do cabaré. A estratégia surge, apoiada numa forte presença musical, que se traduz na utilização de uma vasta panóplia de instrumentos, tais como o piano, a bateria ou o acordeão. Essa ampla dominância da música fica, aliás, claramente enunciada desde a entrada dos espectadores no espaço de representação, através da presentificação quase transparente de muitos dos recursos com que se realiza o espectáculo: os abundantes instrumentos musicais surgem concentrados sobre uma pequena plataforma, colocada à direita, na qual se instalará a instrumentista; ao centro, mais ao fundo, uma cortina vermelha ou pano de boca, apoiado numa estrutura metálica, sugere a possibilidade de multiplicação das áreas de jogo; de um lado e do outro do espaço de representação, diversos cabides e outros adereços completam a paisagem de um espectáculo cuja magia resultará da vida emprestada pelos intérpretes aos objectos e às marionetas inicialmente inertes.

Apoiando-se na lógica de funcionamento do espectáculo de variedades, comum tanto ao circo como ao cabaré, Cabaret Molotov organiza-se em quadros, que se sucedem quase sempre interligados através das mais variadas soluções de continuidade. Depois de uma espécie de prólogo circense, em que um homem-bala é disparado de um canhão contra as cortinas, o primeiro quadro surge dominado pela figura, imediatamente cativante, de Vladimir, uma marioneta de pesado sobretudo castanho, a que o seu principal manipulador empresta um reconhecivel, mas globalmente incompreensivel, linguarejar russo. Estabelecido o diálogo de Vladimir com a trapezista Matrioska, representada por uma mais pequena marioneta com os braços agarrados a um trapézio, assiste-se à enunciação daquela que será a principal marca deste espectáculo e que o seu encenador apresenta como uma "poética do voo": liberto das leis da gravidade pela acção dos seus manipuladores, Vladimir facilmente descola do solo, entregando-se a uma liberdade de movimentos mais ilimitada do que a experimentada pela sua amada Matrioska. 0 mesmo, aliás, acontecerá com a generalidade dos mais variados "objectos cinéticos" convocados e manipulados durante todo o espectáculo, numa espécie de repetida coreografia aérea que reforça o delírio imaginativo em que aposta Cabaret Molotov.

Vladimir regressará, mais tarde, embora desta vez seja a sua voz que se ouve primeiro, no escuro, chamando por Kristina - aparentemente o nome emprestado à intérprete musical de farto cabelo ruivo e saia de muitas camadas de tutu vermelho. Vladimir prolonga a sua ambição aérea, saltando agora numa cama elástica. Por mais de uma vez, cai, tosse, e sobre o solo, no meio do seu contínuo linguarejar, ouve-se algo que parece querer significar "maldita vodka". Alguém haverá de o pendurar num cabide, facto que não o impedirá de continuar a falar, acompanhando a intérprete musical numa melancólica canção francesa. No final, caberá também a Vladimir - uma vez recuperado do seu cabide, mas agora duplicado na figura de corpo inteiro do seu manipulador, equipado com um megafone e um candelabro - encerrar o espectáculo. Numa eloquente figuração da já referida dialéctica entre a marioneta e o seu manipulador, este último Vladimir dará de beber ao primeiro, beijá-lo-á, para depois voltar a fazê-lo desaparecer de cena.

Entre estes três momentos, sucedem-se outros números, nos quais se misturam - como no circo, como no cabaré, mas também como num deliberado, embora não necessariamente explosivo, cocktail cénico - as mais diversas criaturas e processos de lhes dar vida: três cabeças de caniche, que não são mais do que marionetas de mão manipuladas pelos três intérpretes vestidos com fatos de palhaços ricos, interpretam Mack the knife, de Kurt Weill 

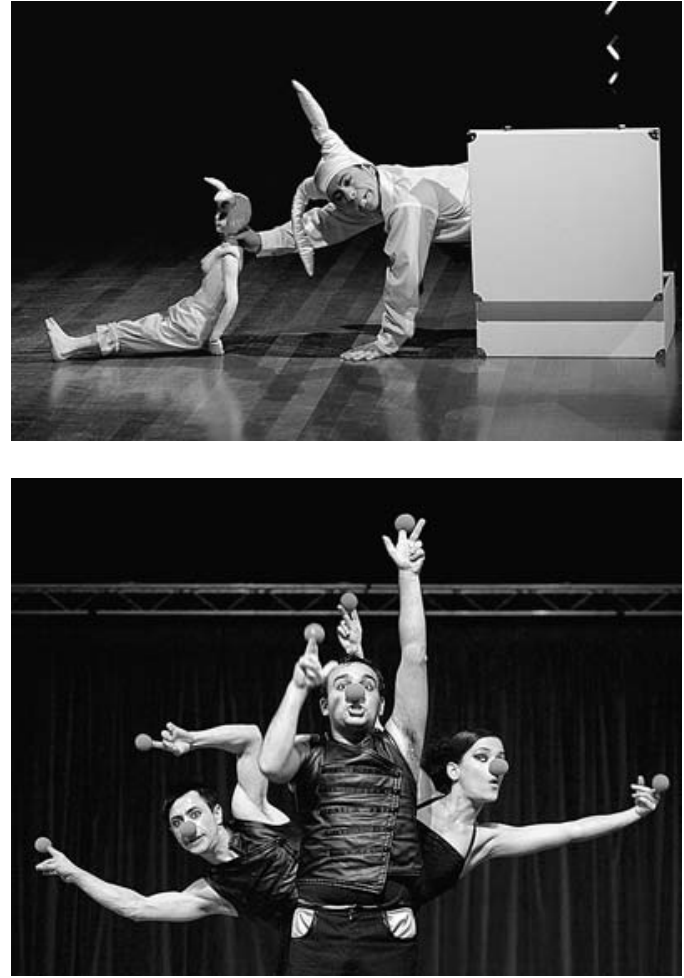

e Bertolt Brecht, ao som de diferentes latidos; três narizes redondos, ou três bolas vermelhas, são animados pelo mesmo conjunto de intérpretes, apostados agora num jogo virtuosístico de sincronização de movimentos e de variações sonoras; dois pequenos bonecos mais antropomórficos, manipulados por uma vara na cabeça, entregam-se a um bailado aéreo sobre uma comprida mesa saída de detrás da cortina; uma bailarina - quase magicamente criada em frente aos olhos dos espectadores, através da imprevista articulação de seis inexpressivos bocados de madeira - executa, sobre a mesma mesa, uma outra espécie de bailado, mais clássico, mas de incomparável elasticidade, desatenta ao perigo constituído pelas chamas de um candelabro colocado na proximidade da sua área de actuação; três pares de sapatos, ainda sobre a mesma mesa, manipulados por intérpretes de marcados chapéus na cabeça, interpretam um breve episódio de ciúme e desafio, ao som de um tango dos Gotan Project; um mais delirante homem-coelho reclama, num linguarejar italiano mais reconhecivel que o russo de Vladimir, um beijo da mulher-coelha que retira da sua mala branca; três marionetas de corpo inteiro executam uma frenética valsa de salão, servida pelos movimentos rápidos, circulares e aéreos dos seus pares humanos; dois palhaços ricos entregam-se às mais cruéis e divertidas tropelias; uma rapariga de meias, ligas brancas e tiras de cor vermelha é manipulada, qual marioneta, por outro dos intérpretes. Mas ainda há o número executado pela actriz que traz consigo, como se fosse uma extensão do seu corpo, um pequeno teatrinho, de cujo palco vão desaparecendo uma casa e o seu habitante, um cão e uma vaca, à medida que um avião vai largando bombas sobre aquele minúsculo cenário; animado por um exigente jogo de manipulação e sonorização, este quadro introduz no espectáculo uma nota de mais tópica e perturbadora actualidade.

Cabaret Molotové uma fascinante proposta cénica, dominada por jogos de alternância de escalas entre os

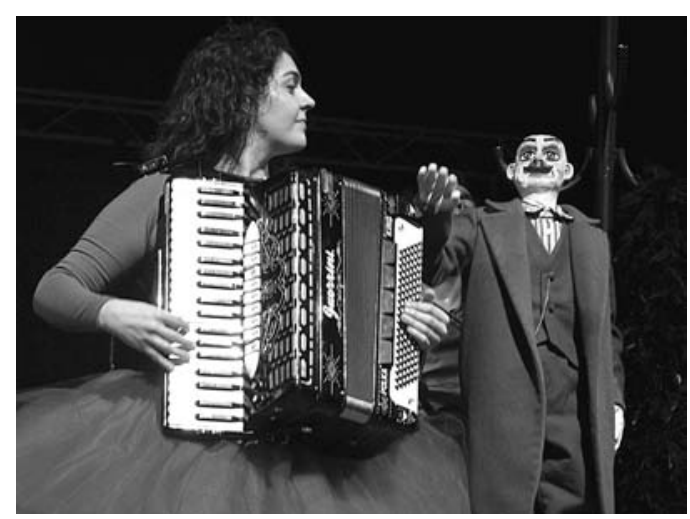

intérpretes e os objectos e servida por demonstrações aparentemente inesgotáveis de humor e de imaginação. A extrema coerência do espectáculo só parece vacilar quando a opção figurativa cede a uma forma mais literal de poesia ou a uma espécie de inesperado mimetismo, uma alternativa aparentemente inaceitável neste universo onírico - como acontece num dos números finais, quando, depois de the terem despejado uma garrafa de champanhe sobre o corpo, uma mulher de lingerie preta recita um poema em espanhol. Se, como no circo ou nas variedades, a sequência de cada um destes números nem sempre é servida por uma mais elaborada lógica de motivação, tal fragilidade dramatúrgica é largamente compensada pelo imparável carrossel de figuras, pela hábil alternância de protagonismo entre a marioneta e os seus manipuladores e, sobretudo, pela contagiante invenção que acompanha a arrebatadora e encantatória execução de todos esses quadros. Edgard Fernandes, Sara Henriques e Sérgio Rolo demonstram ser, simultaneamente, actores, bailarinos, cantores e manipuladores, revelando uma versatilidade e uma energia interpretativas só possiveis pela consequência do trabalho desenvolvido no âmbito de uma tão coerente estética cénica. A instrumentista Shirley Resende completa o quarteto de magníficos intérpretes de um espectáculo que recupera fórmulas e convenções de comprovado apelo comunicativo para as injectar com um renovado fôlego poético e imaginativo.

\section{Referências bibliográficas}

CARDOSO, João Paulo Seara (2005), "Teatros com marionetas", entrevistado por Paulo Eduardo Carvalho e Isabel Alves Costa, Sinais de cena, n. 4, Dezembro, pp. 53-64.

SCHECHTER, Joel (2003), "Back to the Popular Source", in Joel Schechter (ed.), Popular Theatre: A Sourcebook, London and New York, Routledge, pp. 3-11.
Cabaret Molotov, enc. João Paulo Seara Cardoso, Teatro de Marionetas do Porto, 2006 (Edgard Fernandes) fot. Paulo Barata.

Cabaret Molotov, enc. João Paulo Seara Cardoso, Teatro de Marionetas do Porto, 2006 (Edgard Fernandes, Sérgio Rolo, e Sara Henriques), fot. Paulo Barata.

Cabaret Molotov, enc. João Paulo Seara Cardoso, Teatro de Marionetas do Porto, 2006 (Shirley Resende e "Vladimir"), fot. Paulo Barata. 